\title{
Current status of endotherapy for chronic pancreatitis
}

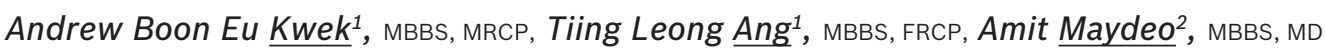

\begin{abstract}
Chronic pancreatitis is associated with varied morphological complications, including intraductal stones, main pancreatic ductal strictures, distal biliary strictures and pseudocysts. Endoscopic therapy provides a less invasive alternative to surgery. In addition, extracorporeal shockwave lithotripsy improves the success rate of endoscopic clearance of intraductal stones. However, recent data from randomised trials have shown better long-term outcomes with surgical drainage for obstructive pancreatic ductal disease. In patients with distal biliary strictures, stent insertion leads to good immediate drainage, but after stent removal, recurrent narrowing is common. Endoscopic drainage of pancreatic pseudocysts has excellent outcome and should be accompanied by pancreatic ductal stenting when a ductal communication is evident. In those who remain symptomatic, endoscopic ultrasonography-guided coeliac plexus block may provide effective but short-term pain relief. In this review, we present the current evidence for the role of endotherapy in the management of patients with chronic pancreatitis.
\end{abstract}

Keywords: chronic pancreatitis, endoscopic treatment

\section{INTRODUCTION}

Chronic pancreatitis is characterised by an ongoing inflammatory process, leading to morphological changes that predominantly cause pain or functional loss. ${ }^{(1)}$ While exocrine or endocrine insufficiency occurs in the late stage of disease, pain is the most common presentation affecting $85 \%-90 \%$ of patients. ${ }^{(2)}$

Although medical therapy, including analgesics, enzyme supplementation, antioxidant and micronutrient therapies, has had some success, better therapeutic approaches are needed for the management of symptomatic patients. ${ }^{(3)} \mathrm{A}$ combination of medical and endoscopic therapy (endotherapy) is usually adopted in patients with symptoms related to obstructive ductal hypertension (from pancreatic ductal stones or strictures), benign biliary ductal strictures or pancreatic pseudocysts. Despite this, some patients continue to have pain, and endoscopic ultrasonography (EUS)-guided coeliac plexus block (CPB) provided a useful adjunct to medical therapy for pain relief. Although surgical drainage may be considered as an alternative to endotherapy, it has higher morbidity and mortality rates. Nonetheless, surgery has been shown to have durability and good success rates over the long-term period.

This review presents the current evidence for the role of endotherapy in patients with chronic pancreatitis. With this knowledge, a balanced approach in the management of this complex and debilitating disease may then be adopted.

\section{PANCREATIC DUCTAL STONES}

In $50 \%-90 \%$ of patients with longstanding chronic pancreatitis, pancreatic ductal stones are detected at presentation and are generally considered to be the effect of the disease rather than the cause. ${ }^{(4,5)}$ However, these stones contribute to ductal hypertension by impeding pancreatic juice outflow, and thus leading to continual pain. The aim of endotherapy is to decompress the main pancreatic duct (MPD) by performing complete stone clearance and ductal drainage, leading to MPD diameter reduction. The subsequent pain relief experienced by patients after ductal drainage supports the postulate of ductal hypertension as a cause of their abdominal pain. Treatment for pancreatic ductal stones should only be considered if the patient experiences pain.

Patient selection for endotherapy begins with plain radiography and magnetic resonance cholangiopancreatography (MRCP). Radiographic assessment is best performed using a fluoroscopy machine with a rotatable arm, delineating the stone distribution, density and morphology. MRCP outlines the ductal morphology, depicting the presence of stones and ductal anomalies such as divisum or strictures. Factors favouring successful stone clearance by endotherapy include: three or less stones; location of stones at the pancreatic head and/or body; absence of stricture downstream to the stone; stone size of $10 \mathrm{~mm}$ or less; and absence of impacted stones. ${ }^{(6)}$

In addition, symptomatic patients with pancreatic ductal stones are considered for extracorporeal shockwave lithotripsy (ESWL), especially those who have stones that are more than $5 \mathrm{~mm}$ in size. The objective of ESWL is to completely pulverise the stones until they are almost a granular powder form. Prior to the introduction of ESWL in 1989, surgery was the main option for extracting endoscopically nonremovable stones. ${ }^{(7)}$ Pre-endotherapy ESWL confers a higher rate of successful endotherapy to achieve complete ductal clearance of the MPD stones. In a retrospective series of 125 patients, less than $10 \%$ of them had successful endoscopic ductal clearance without prior ESWL. ${ }^{(8)}$ As pancreatic stones consist of radio-opaque calcium salts with carbonate and phosphate, they can be effectively fragmented by ESWL in about $90 \%$ of patients, with most $(90 \%)$ requiring less than three sessions. ${ }^{(9,10)}$ Other studies have reported successful ESWL rates of $75 \%-100 \%$, with subsequent MPD clearance in 37.5\%-100.0\%. ${ }^{(11,12)}$ ESWL followed by endotherapy is the accepted initial step for most patients with stones larger than $5 \mathrm{~mm}$ in the MPD.

${ }^{1}$ Department of Gastroenterology and Hepatology, Changi General Hospital, Singapore, ${ }^{2 B}$ Baldota Institute of Digestive Sciences, Global Hospital, Mumbai, India Correspondence: Dr Andrew Kwek Boon Eu, Consultant, Department of Gastroenterology and Hepatology, Changi General Hospital, 2 Simei Street 3 , Singapore 529889. andrew_kwek@cgh.com.sg 
Table I. Selected series utilising extracorporeal shockwave lithotripsy followed by endotherapy for treatment of chronic calcific pancreatitis.

\begin{tabular}{|c|c|c|c|c|c|}
\hline Study (year) & $\begin{array}{l}\text { No. of } \\
\text { patients }\end{array}$ & $\begin{array}{c}\text { Ductal } \\
\text { clearance }(\%)\end{array}$ & $\begin{array}{l}\text { Pain } \\
\text { relief }(\%)\end{array}$ & $\begin{array}{l}\text { Follow-up } \\
\text { duration }\end{array}$ & Complication \\
\hline Tandan et al (2013) $)^{(13)}$ & $\begin{array}{l}\text { a) } 364 \\
\text { b) } 272\end{array}$ & 100.0 & $\begin{array}{l}\text { a) } 68.7 \\
\text { b) } 60.3\end{array}$ & $\begin{array}{l}\text { a) } 24-60 \mathrm{mth} \\
\text { b) }>60 \mathrm{mth}\end{array}$ & Not reported \\
\hline Seven et al (2012) $)^{(14)}$ & 120 & - & 85.0 & $4.3 \mathrm{yr}$ & Not reported \\
\hline Tandan et al $(2010)^{(10)}$ & 1,006 & 93.0 & 84.0 & 6 mth & $\begin{array}{l}\text { Ecchymosis }(n=185) \text {, haematemesis }(n=2) \text {, } \\
\text { post-ERCP pancreatitis }(n=29)\end{array}$ \\
\hline Tadenuma et al (2005) ${ }^{(15)}$ & 117 & 56.0 & 63.0 & $6.5 \mathrm{yr}$ & $\begin{array}{l}\text { Pancreatitis }(n=8) \text {, post-sphincterotomy } \\
\text { bleed }(n=2) \text {, neuropathy }(n=1)\end{array}$ \\
\hline Delhaye et al (2004) $)^{(16)}$ & 56 & 86.0 & 66.1 & $14.4 \mathrm{yr}$ & $\begin{array}{l}\text { Biliary and/or pancreatic sepsis }(n=12) \text {, } \\
\text { mild pancreatitis }(n=2)\end{array}$ \\
\hline Brand et al $(2000)^{(17)}$ & 48 & 75.0 & 82.0 & 7 mth & Pancreatic sepsis $(n=1)$ \\
\hline Costamagna et al (1997) & 35 & 74.0 & 71.9 & $26.8 \mathrm{mth}$ & $\begin{array}{l}\text { Pancreatic sepsis }(n=3) \text {, cholangitis }(n=3) \text {, } \\
\text { gastric submucosal haematoma }(n=1) \text {, } \\
\text { pancreatic fluid collection }(n=1)\end{array}$ \\
\hline Delhaye et al (1992) ${ }^{(18)}$ & 122 & 59.0 & 85.0 & $14 \mathrm{mth}$ & $\begin{array}{l}\text { Pancreatic sepsis }(n=25) \text {, } \\
\text { cholangitis }(n=14) \text {, acute pancreatitis }(n=5)\end{array}$ \\
\hline Sauerbruch et al (1992) ${ }^{(19)}$ & 24 & 71.0 & 83.3 & $24 \mathrm{mth}$ & Mild pancreatitis $(n=2)$ \\
\hline
\end{tabular}

ERCP: endoscopic retrograde cholangiopancreatography

Endoscopic clearance of stone fragments is performed via endoscopic retrograde cholangiopancreatography (ERCP), which begins with cannulation of the pancreatic orifice and contrast instillation to delineate the ductal anatomy and assess the location of the stone fragments. Subsequently, pancreatic sphincterotomy followed by irrigation of the pancreatic duct with saline solution, and balloon or basket trawling are performed. In patients with pancreas divisum, ductal access via the minor papilla is followed by minor papilla sphincterotomy. When ductal strictures are present, these may be dilated using radial expansion balloon, dilator catheters or the Soehendra stent retriever, in recalcitrant cases. Plastic stents are inserted in patients with ductal strictures, or when residual stones cannot be removed completely.

In a large series of patients who underwent ESWL and endotherapy, pain relief was reported in 711 of 846 (84\%) at six months follow-up, accompanied by a significant decrease in analgesic use. ${ }^{(10)}$ Recently published long-term data showed pain relief in $60 \%-85 \%$ of patients at a follow-up of more than four years. ${ }^{(13,14)}$

Table I summarises selected series from various expert centres that have adopted the aforementioned approach. Fig. 1 shows the computed tomography (CT) features of hyperdense pancreatic stones at the head of the pancreas, with upstream dilation of the pancreatic and biliary ducts. A small $(4 \mathrm{~cm})$ pancreatic pseudocyst is seen at the tail region of the pancreas. After ESWL and endoscopic clearance of the fragmented stones, the follow-up image (Fig. 2) shows resolution of both the dilated ducts and pseudocyst.

Ecchymosis in the targeted ESWL region is the most common complication, affecting $18.5 \%$ of patients. ${ }^{(10)}$ Abdominal pain occurs in $12.1 \%$ of patients who undergo ESWL and endotherapy. Occasionally, exacerbation of pancreatitis also occurs. ${ }^{(20)}$ Conservative management usually leads to resolution. Other reported complications include biliary or pancreatic sepsis,

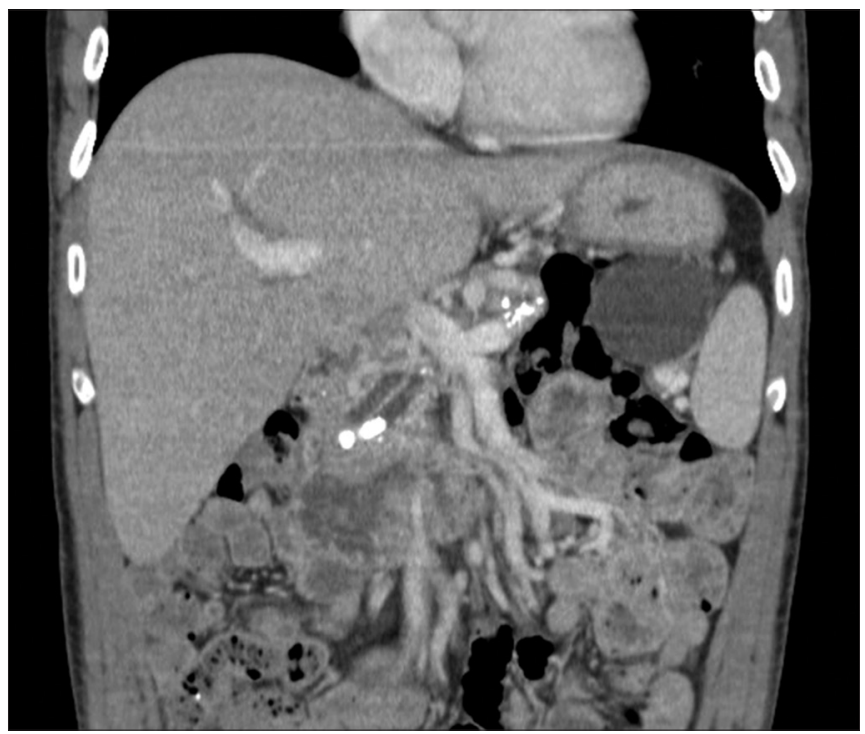

Fig. 1 CT image shows the presence of hyperdense pancreatic stones at the head of the pancreas, with upstream dilation of the pancreatic and biliary ducts. A small $(4 \mathrm{~cm})$ pancreatic pseudocyst is seen at the tail region of the pancreas.

pancreatic fluid collection formation and gastric submucosal haematoma. ${ }^{(11)}$

\section{ESWL ALONE}

In Ohara et al's study, ${ }^{(21)}$ ESWL without subsequent endotherapy for stone extraction was reported to successfully clear intraductal stones in 24 of 32 patients (75\%). This was accompanied by pain relief in $79 \%$ of patients over a mean follow-up period of 44 months. $^{(21)}$ In a randomised trial of 55 patients, comparing ESWL alone with ESWL followed by endoscopic drainage of the MPD, both groups had similar pain relief of about $40 \%$ at two years follow-up. ${ }^{(22)}$ These findings suggest that in well-selected patients, post-ESWL endotherapy may not always be necessary to provide good clinical outcome and that ESWL alone may be the more cost-effective approach. 


\section{MPD STRICTURES}

MPD strictures are classified as a dominant stricture in the presence of at least one of the following features: upstream MPD dilation of $\geq 6 \mathrm{~mm}$ in diameter; prevention of contrast medium outflow alongside a 6-Fr catheter inserted upstream from the stricture; or abdominal pain during continuous infusion of a nasopancreatic catheter inserted upstream from the stricture with $1 \mathrm{~L}$ saline for $12-24 \mathrm{hr} .{ }^{(23)}$ Fig. 3 shows the presence of an MPD stricture at the pancreatic genu, with upstream dilation of the MPD and side branches. The management of MPD strictures includes pancreatic sphincterotomy, stricture dilation and temporary stenting. When stricture dilation is unsuccessful with bougies or balloons, the Soehendra stent retriever may be used to gradually bore through the fibrotic segment. Stenting is possible in $85 \%-98 \%$ of cases, with immediate pain relief in $65 \%-95 \%$. ${ }^{(23)}$ On subsequent follow-up over 14-58 months, $32 \%-68 \%$ of patients are expected to continue to experience pain relief. ${ }^{(23)}$

As chronic pancreatitis is a risk factor for pancreatic cancer, a high index of suspicion should be employed when managing patients with MPD strictures. Imaging with dedicated CT of the pancreas or EUS may be utilised to exclude the presence of associated pancreatic masses. Stent placement includes the use of plastic polyethylene stents or self-expandable metallic stents (SEMS). The main objective of MPD stenting is to allow adequate dilation of the stricture, with sustained flow even after the stent is removed. Stenting may also be used as a temporary drainage procedure to predict symptomatic improvement should a surgical alternative be considered.

\section{Plastic stents}

Usually plastic stents with sizes ranging from 7-, 8.5- to $10-\mathrm{Fr}$ are used in either a single or multiple fashion. Multiple stent placement is associated with a high rate of stricture resolution (95\%), as shown in a study involving 19 patients, but this does not always translate to complete symptomatic relief, as the pathophysiology of chronic pancreatitisrelated pain is complex. ${ }^{(24)}$ Besides ductal hypertension, oxidative stress, neuroimmune modulation, and changes in neural pathways and synapses are contributing factors to ongoing nociception. ${ }^{(25)}$ Predictors of good outcome after pancreatic duct stenting include stricture position at the head of the pancreas, upstream dilation of MPD, absence of pancreas divisum and nonalcoholic aetiology of chronic pancreatitis. ${ }^{(26,27)}$ Complications related to pancreatic stenting occur in $6 \%-39 \%$ of patients. While mild pancreatitis is most common, stent migration and pancreatic abscesses requiring surgery have been reported. ${ }^{(23)}$

Table II provides a summary of selected series of plastic stenting for chronic pancreatitis-related MPD strictures. At our centre, we perform three-monthly reassessments after initial MPD stenting. During these reassessments, if the stricture has resolved (evidenced by good outflow of contrast from the proximal duct, easy passage of a 7-Fr catheter, diminished focal narrowing), the stent is permanently removed.

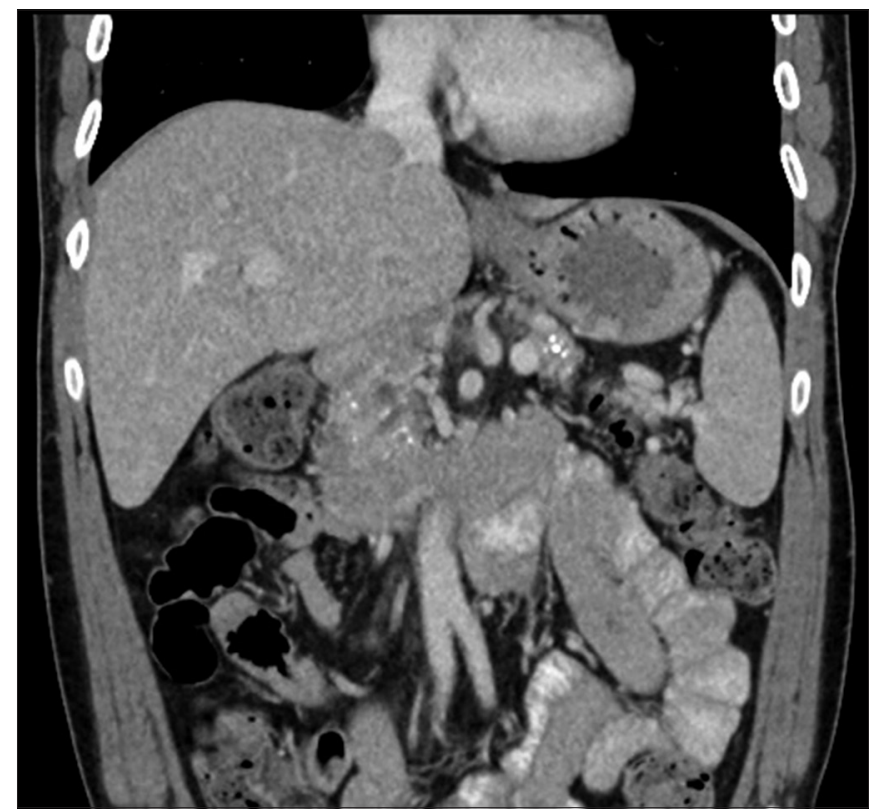

Fig. 2 CT image shows the resolution of both the dilated ducts and pseudocyst, following extracorporeal shockwave lithotripsy and endotherapy.

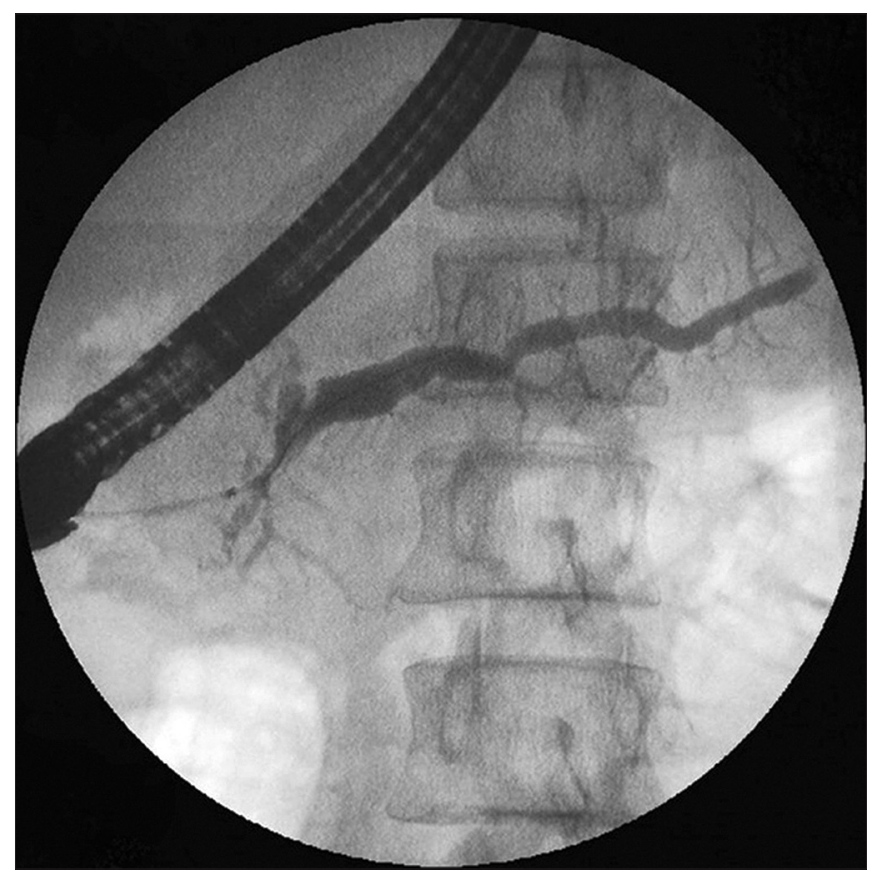

Fig. 3 Pancreatogram shows a main pancreatic duct stricture at the pancreatic genu, with upstream dilation of the main duct and its side branches.

\section{Self-expandable metallic stents}

Since the late 1990s, SEMS have been used experimentally for benign pancreatic duct strictures. ${ }^{(30)}$ More recently, the feasibility and safety of fully covered SEMS for refractory strictures were reported in 13 patients by Park et al. ${ }^{(31)}$ Although stent placement was successful in all the patients, stent migration was a significant problem, occurring in five patients (one proximal and four distal). Despite this, resolution of the strictures was documented in all patients at follow-up ERCP two months later. Other complications include mild acute pancreatitis (two patients) and cholestatic liver dysfunction (two patients). ${ }^{(31)}$ 
Table II. Selected series utilising plastic stenting for chronic pancreatitis-related main pancreatic duct strictures.

\begin{tabular}{|c|c|c|c|c|c|c|c|}
\hline Study (year) & $\begin{array}{l}\text { No. of } \\
\text { patients }\end{array}$ & $\begin{array}{l}\text { Initial } \\
\text { pain } \\
\text { relief }(\%)\end{array}$ & $\begin{array}{c}\text { Stent } \\
\text { duration } \\
\text { (mth) }\end{array}$ & $\begin{array}{l}\text { Pain relief } \\
\text { after stent } \\
\text { removal (\%) }\end{array}$ & $\begin{array}{l}\text { Follow-up } \\
\text { duration } \\
\text { (mth) }\end{array}$ & Complication & $\begin{array}{l}\text { Surgery } \\
(\%)\end{array}$ \\
\hline Costamagna et al (2006) $)^{(24)}$ & $19^{*}$ & 100 & 7 & 84 & 38 & $\mathrm{Nil}$ & Nil \\
\hline Eleftherladis et al (2005) ${ }^{(27)}$ & 100 & 100 & 23 & 62 & 69 & $\begin{array}{l}\text { Sepsis }(11 \%) \text {, acute pancreatitis }(12 \%) \text {, } \\
\text { stent impaction }(2 \%) \text {, stent migration }(2 \%)\end{array}$ & 4 \\
\hline Vitale et al $(2004)^{(28)}$ & 89 & 83 & 5 & 68 & 43 & Mild pancreatitis $(18 \%)$, cholangitis $(1 \%)$ & 12 \\
\hline Binmoeller et al (1995) ${ }^{(29)}$ & 93 & 74 & 15.7 & 65 & 58 & $\begin{array}{l}\text { Mild pancreatitis }(4 \%) \text {, pancreatic } \\
\text { abscess }(2 \%)\end{array}$ & 26 \\
\hline
\end{tabular}

* Multiple stents approach: each patient had a median number of 3 stents, with diameters ranging from $8.5-$ to $11.5-\mathrm{Fr}$

In 2010, the same authors published their experience using a modified, fully covered SEMS (Niti-S Pancreatic Stent [bumpy type]; Taewoong Medical, Seoul, South Korea) that had antimigration features. ${ }^{(32)}$ In this study, no stent migration occurred in all 32 patients. Additionally, all stents were easily removed at three months and pancreatography showed resolution of duct strictures. However, five patients developed asymptomatic de novo focal pancreatic strictures. In the subsequent follow-up over a mean of five months, three patients had symptomatic recurrent strictures, requiring repeat stenting in two patients and surgery in one patient.

\section{PANCREATIC DUCTAL STONES AND/OR STRICTURES: ENDOTHERAPY VS. SURGERY}

Surgery is usually considered for patients who have poor response to medical therapy or endotherapy. The most common surgical drainage procedure is the modified Puestow operation or lateral pancreaticojejunostomy. In patients with pancreatic head inflammatory mass, duodenum-preserving pancreatic head resection or pancreaticoduodenectomy is performed. ${ }^{(33)}$

Two randomised controlled trials (RCTs) compared endotherapy with surgery for patients with painful uncomplicated chronic pancreatitis. Díte et al ${ }^{(34)}$ randomised 72 patients to receive either endotherapy or surgery for painful obstructive chronic pancreatitis with strictures and/or stones. Although initial pain relief was similar, fewer patients in the endotherapy group had complete absence of pain at five years (15\% vs. $34 \%)$. ${ }^{(34)}$ While it appears that surgery had better long-term success, it is important to note that in this trial, patients in the endotherapy group did not receive ESWL, and the protocol also excluded cumulative stenting or repeat sessions for recurrent symptoms, thus reducing the maximum potential of endotherapy to provide good clinical outcome.

In the second RCT, which included 39 patients, Cahen et al reported a lower rate of pain relief at two years follow-up in the endotherapy group compared with the surgery group (32\% vs. $75 \%){ }^{(35)}$ They further reported that at long-term (79 months) follow-up, additional drainage procedure was required in $68 \%$ of patients in the endotherapy group and $5 \%$ of patients in the surgical group. ${ }^{(36)} \mathrm{Also}, 47 \%$ of patients in the endotherapy group eventually underwent surgery. ${ }^{(36)}$ This trial was limited by a lower than usual overall technical success $(53 \%)$ in the endotherapy group, perhaps due to the high proportion ( $84 \%$ ) of patients who had pancreatic duct strictures. ${ }^{(35)}$

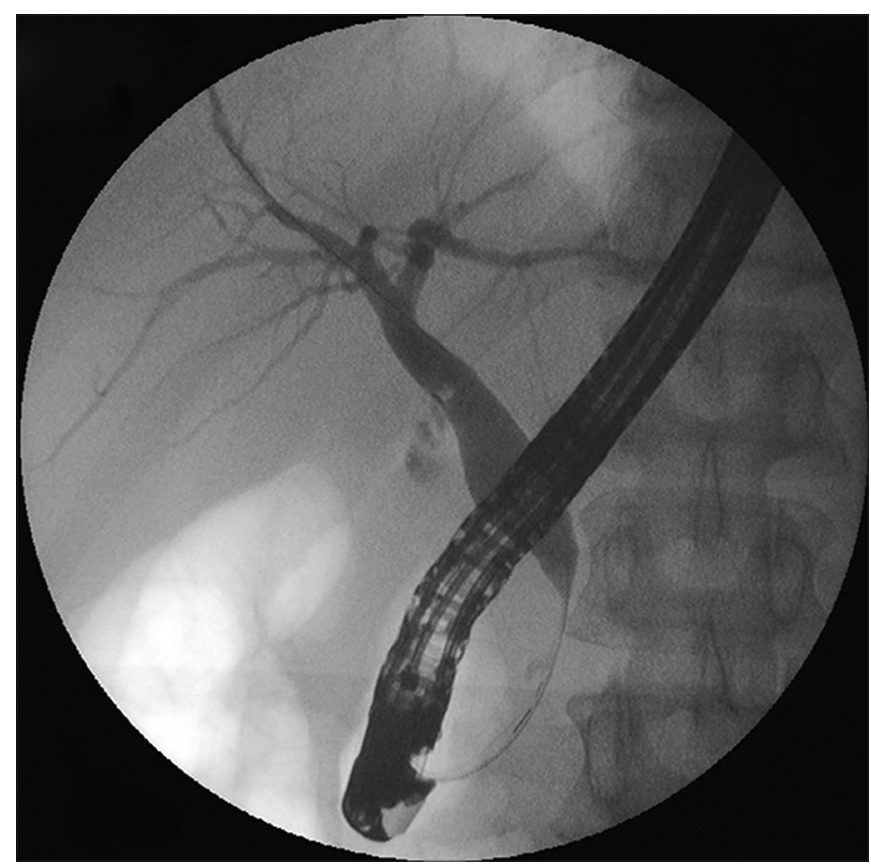

Fig. 4 Cholangiogram shows a stricture of the intrapancreatic portion of the common bile duct.

The aforementioned RCT results provide relevant data that may be used for discussion with patients, the majority of whom would prefer a less invasive approach due to the significant morbidity and mortality of surgery $(18 \%-53 \%$ and $0 \%-5 \%$, respectively, for resections, and $0 \%-4 \%$ mortality for MPD drainage). ${ }^{(23)}$ Also, although the long-term results show that surgery provides more durable pain relief, endotherapy may reduce the need for surgical procedures, act as a bridge to surgery in poor surgical candidates, or predict the response to surgical drainage.

\section{BENIGN BILIARY STRICTURES}

Distal common bile duct strictures (Fig. 4) occur in up to $46 \%$ of patients with chronic pancreatitis, as a consequence of inflammation-induced periductal fibrosis. ${ }^{(37,38)}$ It is more frequent in patients with advanced disease, especially in those with chronic calcific pancreatitis. In the patient who presents with jaundice alone, conservative approach with close monitoring of liver function tests may be considered, as the jaundice may resolve after an acute inflammatory episode has resolved. Intervention is recommended in the presence of symptoms, secondary biliary cirrhosis, biliary stones, and stricture progression. In the 
asymptomatic patient, treatment may be considered if the serum alkaline phosphatase is elevated to more than two times the upper limit of normal values and/or elevated serum bilirubin for longer than one month. ${ }^{(23)}$ Similar to MPD strictures, a high index of suspicion for a malignant aetiology should be adopted and appropriate histological sampling taken when managing chronic pancreatitis-related biliary strictures.

Biliary drainage may be performed with single or multiple side-by-side plastic stents or SEMS. To facilitate the insertion of a plastic stent, dilation of the stricture using a dilator catheter or balloon dilator may be necessary. Due to its fibrotic nature, the success of endotherapy for chronic pancreatitis-related biliary stricture is poor in most cases. ${ }^{(39)}$ Long-term success ranges from $10 \%$ to $92 \%$, and surgical drainage is required in up to $49 \%$ of patients. ${ }^{(23)}$

\section{Plastic stents}

According to Kahl et al's study, ${ }^{(40)}$ persistence of the stricture was encountered at one year in nearly $70 \%$ of the 61 patients treated with single stents (10- or $11.5-\mathrm{Fr}$ ). In the group of patients with alcoholic chronic pancreatitis, the presence of pancreatic head calcifications was a predictor of poor response to endoscopic stenting. ${ }^{(40)}$ Another study that focused on the insertion of multiple plastic biliary stents (7.5- to 10-Fr; $1-5$ stents) increasingly in 29 patients at three-monthly intervals showed that after two years of stent placement, only $60 \%$ had stent-free recovery at a follow-up period of about one year. ${ }^{(41)}$

\section{SEMS}

The use of fully covered SEMS for benign biliary strictures is hampered by stent migration. In a small study ${ }^{(42)}$ involving six patients, proximal migration of the stent occurred in two patients, one of which was still retrievable. After 4-6 months, the stents were safely retrieved in four patients with stricture resolution. However, recurrent stricture was seen in one patient after six months. ${ }^{(42)}$

In Poley et al's study, ${ }^{(43)}$ fully covered SEMS with proximal and distal lassos for retrieval (Hanaro; MI Tech, Seoul, Korea) were used in 23 patients with benign biliary strictures, 13 of whom were due to chronic pancreatitis. The authors found that, compared to other aetiologies, patients with chronic pancreatitis had a lower success rate ( $80 \%$ vs. $46 \%$ ) for stricture resolution after SEMS removal. Stent placement was over a mean duration of 5.5 months and all stents were easily removed. Soon after stent placement, pain occurred in 13 patients, but was easily managed with analgesics. Other complications include cholecystitis $(n=1)$, cholangitis due to stent migration $(n=1)$ or stent blockage $(n=2)$, and worsening of chronic pancreatitis $(n=2){ }^{(43)}$

Better success rate was reported in 20 patients with partially covered SEMS for chronic pancreatitis-related biliary strictures. ${ }^{\left({ }^{44}\right)}$ In this study, 18 patients had persistent stricture resolution six months after stent removal. Median stent duration was five months. Although promising, placement of SEMS for benign biliary strictures remains investigational, and the comparison of SEMS, multiple plastic stents and surgery awaits further research.

\section{PANCREATIC PSEUDOCYSTS}

Pancreatic pseudocyst (PP), an amylase-rich fluid collection enclosed by a wall of fibrous granulation tissue, arises from the disruption of the MPD or its branches, as a consequence of acute pancreatitis, pancreatic trauma or chronic pancreatitis. ${ }^{(45,46)}$ About $20 \%-40 \%$ of patients with chronic pancreatitis develop PP. ${ }^{(47)}$ Indications for treatment include the presence of infection, an enlarging PP and symptoms related to PP (abdominal pain, gastric outlet obstruction or jaundice). Besides these indications, treatment of pseudocysts may be considered in view of its low rate $(0 \%-9 \%)$ of spontaneous resolution in the setting of chronic pancreatitis. $^{(48)}$

Although easily performed, simple cyst aspiration is limited by a high recurrence rate of more than $70 \% .{ }^{(49)}$ Therefore, longerterm drainage is necessary for good outcome and durability. PP drainage may be performed via percutaneous, endoscopic or surgical approaches. Percutaneous catheter drainage has a short-term success rate of $84 \%$ and a recurrence rate of $7 \%$, but prolonged placement of an external catheter is frequently complicated by the development of pancreatic-cutaneous fistulas. ${ }^{(49-51)}$ To avoid this, endoscopic drainage allows for internal drainage via a communication between the PP and the stomach or duodenum. It is usually performed by puncturing the cyst under EUS guidance, which avoids the occasional inadvertent puncture of blood vessels during the direct puncture method. Following dilation of the puncture site, at least two doublepigtail plastic stents are placed to allow continual drainage of the PP fluid. These stents should only be retrieved after crosssectional imaging has confirmed the resolution of the cyst and at least two months after stenting. ${ }^{(23)} \mathrm{A}$ retrospective analysis of 92 patients who underwent endoscopic drainage for PP showed a high initial technical success rate of $97 \%$, but during a median follow-up period of 43 months, 15 patients required alternative therapy for persistent or recurrent cyst; the overall success rate of endotherapy was $71 \% .{ }^{(52)}$

Evaluation of the pancreatic duct is relevant for addressing predisposing factors to recurrence of pseudocyst. In the context of chronic pancreatitis, pancreatic duct stones and strictures are important predisposing factors and should be treated as previously outlined. In the case of acute exacerbation of chronic pancreatitis, a persistent pancreatic leak may occur, although this is usually more relevant in the context of severe acute pancreatitis than chronic pancreatitis. Pancreatic duct evaluation is usually performed with MRCP, which is noninvasive. ERCP may be performed to evaluate any pancreatic duct leak that communicates with the pseudocyst. This is crucial, as pancreatic duct disruption is present in $40 \%-60 \%$ of patients with peripancreatic fluid collections. In the presence of an MPD disruption, better outcome is seen in successful stent bridging, as it allows preferential downstream flow of the pancreatic juice. ${ }^{(53)}$

The outcome of surgical intervention for PP was compared with endoscopic drainage in a randomised controlled trial, which demonstrated that endoscopic drainage and surgical cystgastrostomy had similar success, complications and reintervention rates; however, in the endoscopy group, shorter 
length of stay, better scores for physical and mental health, and lower costs were observed. ${ }^{(54)}$ In a comprehensive review, Rosso et al ${ }^{(55)}$ reported that endoscopic drainage yields a technical success rate of over $80 \%-90 \%$. Compared to surgery, endoscopic drainage has similar morbidity $(16.0 \%$ vs. $13.3 \%)$ and longterm pseudocyst recurrence $(9.8 \%$ vs. $10.7 \%$ ) rates, but a lower mortality rate $(0.2 \%$ vs. $2.5 \%) .{ }^{(55)}$

Serious complications related to endoscopic drainage of PP include bleeding, perforation and infection. Morbidity and mortality rates have been reported to be $13.0 \%$ and $0.3 \%$, respectively. ${ }^{(23)}$ Prior to endoscopic drainage of $\mathrm{PP}$, elective angiographic embolisation of a detected pseudoaneurysm may potentially reduce the catastrophic bleeding risk of aneurysmal rupture. The endoscopist should also ensure that the PP has a well-defined wall prior to attempts to dilate the puncture site. Also, the use of antibiotic prophylaxis is generally supported by consensus opinion, and its duration of use is based on the success of adequate drainage and the absence of debris within the PP.

A recent improvement to endoscopic drainage is the introduction of a fully covered metallic stent designed to overcome the higher migration rates of standard enteral SEMS. ${ }^{(56)}$ The NAGI fully covered SEMS (Taewoong-Medical Co, Seoul, South Korea) has acute-angled flare ends that provide better anchoring at the gastric and pseudocyst walls. Its large internal diameter of $10 \mathrm{~mm}$ or $16 \mathrm{~mm}$ and lengths of $1-3 \mathrm{~cm}$ provide a larger fistula diameter for better drainage compared with plastic stents. In our early experience of this stent, we found that no stent migration occurred, drainage of the pancreatic collection was effective and the stent was easily retrieved subsequently.

\section{EUS-GUIDED COELIAC PLEXUS BLOCK}

Pain management in patients with chronic pancreatitis follows the World Health Organization analgesic step-up ladder principle, starting with non-opioid analgesics such as NSAIDs, and progressing to mild or stronger opioids depending on the patient's response. When these and other adjuvant therapies such as pancreatic enzymes and/or antioxidants fail to relieve pain or is complicated by intolerance or dependence, EUS-guided CPB may be considered. It is performed by injecting a mixture of corticosteroids and local anaesthetic into the coeliac plexus nerves to disrupt the afferent pain signals. While other approaches to performing CPB (including CT, fluoroscopy or US-guided techniques) have been used, EUS-guided CPB has been shown to be superior, with better pain relief and lower cost, and it is the preferred choice of the patient. ${ }^{(57,58)}$ Moreover, EUS-guided CPB avoids the risk of neurological deficits, specifically paraplegia, which is associated with the posterior transcutaneous approach.

EUS-guided CPB has success rates of $50 \%-60 \%$ in patients with chronic pancreatitis-related pain. ${ }^{(59,60)}$ In contrast, patients with pancreatic cancer-related pain have better pain response to $\mathrm{CPB}$ or neurolysis, with $70 \%-80 \%$ of pain relief. ${ }^{(59,60)}$ The lower success rate in chronic pancreatitis may be due to the complex pathophysiological pain mechanism in this group of patients. Ethanol-induced coeliac plexus neurolysis for patients with chronic pancreatitis remains controversial and is usually reserved for cancer-related intractable pain.

Pain relief from EUS-guided CPB is temporary. In a study involving 90 patients, $55 \%$ had significant initial improvement in pain scores, but this reduced to $10 \%$ after 24 weeks. ${ }^{(61)}$ Similarly, studies reviewed in a meta-analysis reported a median pain relief duration of 11-37 days post procedure, with persistent benefit in some patients for up to 48 weeks. ${ }^{(60)}$

The most common complication of EUS-guided CPB is transient diarrhoea secondary to sympathetic denervation. Other complications include hypotension, pancreatitis and local infections. These may occur in up to one-third of patients. ${ }^{(60)}$ They are usually responsive to conservative management with intravenous fluids, anti-diarrhoeal agents or prophylactic antibiotics.

\section{MILD CHRONIC PANCREATITIS}

Based on the Cambridge morphological classification, patients with mild chronic pancreatitis may also present with pain. ${ }^{(62)}$ However, there is limited data to support the use of endotherapy (pancreatic sphincterotomy or stenting) in patients who do not have main duct dilation, strictures or stones. Previous studies either included only a small number of patients with mild chronic pancreatitis or did not perform subgroup analysis. ${ }^{(63,64)}$ Therefore, the general recommendation of endotherapy for painful chronic pancreatitis currently applies only to patients with moderate or marked features of chronic pancreatitis. Nonetheless, EUS-guided CPB remains a viable option to provide pain relief in this group of patients.

\section{CONCLUSION}

Pancreatic endotherapy provides a less invasive alternative to surgery for chronic pancreatitis-related ductal hypertension. Although endotherapy has clinical outcomes that are comparable to surgery and has lower morbidity and mortality rates, recent long-term outcome data appears to favour surgery. Nevertheless, endotherapy remains a cornerstone in the management of patients with chronic pancreatitis, as it may reduce the need for surgical procedures, act as a bridge to surgery in poor surgical candidates, or predict the response to surgical drainage. In those who fail medical and endoscopic therapy, surgical therapy is not precluded and may still be considered.

\section{REFERENCES}

1. Etemad B, Whitcomb DC. Chronic pancreatitis: diagnosis, classification, and new genetic developments. Gastroenterology 2001; 120:682-707.

2. Braganza JM, Lee SH, McCloy RF, McMahon MJ. Chronic pancreatitis. Lancet $2011 ; 377: 1184-97$.

3. Talukdar R, Reddy DN. Pain in chronic pancreatitis: managing beyond the pancreatic duct. World J Gastroenterol 2013; 19:6319-28.

4. Maydeo A, Soehendra N, Reddy N, Bhandari S. Endotherapy for chronic pancreatitis with intracanalar stones. Endoscopy 2007; 39:653-8.

5. Ammann RW, Muench R, Otto R, et al. Evolution and regression of pancreatic calcification in chronic pancreatitis. A prospective long-term study of 107 patients. Gastroenterology 1988; 95:1018-28.

6. Sherman S, Lehman GA, Hawes RH, et al. Pancreatic ductal stones: frequency of successful endoscopic removal and improvement in symptoms. Gastrointest Endosc 1991; 37:511-7.

7. Sauerbruch T, Holl J, Sackmann M, Paumgartner G. Extracorporeal shock wave lithotripsy of pancreatic stones. Gut 1989; 30:1406-11. 
8. Farnbacher MJ, Schoen C, Rabenstein T, et al. Pancreatic duct stones in chronic pancreatitis: criteria for treatment intensity and success. Gastrointest Endosc 2002; 56:501-6.

9. Nguyen-Tang T, Dumonceau JM. Endoscopic treatment in chronic pancreatitis, timing, duration and type of intervention. Best Pract Res Clin Gastroenterol 2010; 24:281-98.

10. Tandan M, Reddy DN, Santosh D, et al. Extracorporeal shock wave lithotripsy and endotherapy for pancreatic calculi-a large single center experience. Indian J Gastroenterol 2010; 29:143-8.

11. Costamagna G, Gabbrielli A, Mutignani M, et al. Extracorporeal shock wave lithotripsy of pancreatic stones in chronic pancreatitis: immediate and medium-term results. Gastrointest Endosc 1997; 46:231-6.

12. Guda NM, Partington S, Freeman ML. Extracorporeal shock wave lithotripsy in the management of chronic calcific pancreatitis: a meta-analysis. JOP 2005; 6:6-12

13. Tandan M, Reddy DN, Talukdar R, et al. Long-term clinical outcomes of extracorporeal shockwave lithotripsy in painful chronic calcific pancreatitis. Gastrointest Endosc 2013; 78:726-33.

14. Seven G, Schreiner MA, Ross AS, et al. Long-term outcomes associated with pancreatic extracorporeal shock wave lithotripsy for chronic calcific pancreatitis. Gastrointest Endosc 2012; 75:997-1004.e1.

15. Tadenuma $H$, Ishihara $T$, Yamaguchi $T$, et al. Long-term results of extracorporeal shockwave lithotripsy and endoscopic therapy for pancreatic stones. Clin Gastroenterol Hepatol 2005; 3:1128-35.

16. Delhaye $M$, Arvanitakis $M$, Verset $G$, Cremer $M$, Devière J. Long-term clinical outcome after endoscopic pancreatic ductal drainage for patients with painful chronic pancreatitis. Clin Gastroenterol Hepatol 2004 2:1096-106.

17. Brand B, Kahl M, Sidhu S, et al. Prospective evaluation of morphology, function, and quality of life after extracorporeal shockwave lithotripsy and endoscopic treatment of chronic calcific pancreatitis. Am J Gastroenterol 2000; 95:3428-38

18. Delhaye M, Vandermeeren A, Baize M, Cremer M. Extracorporeal shockwave lithotripsy of pancreatic calculi. Gastroenterology 1992; 102:610-20

19. Sauerbruch T, Holl J, Sackmann M, Paumgartner G. Extracorporea lithotripsy of pancreatic stones in patients with chronic pancreatitis and pain: a prospective follow up study. Gut 1992; 33:969-72.

20. van der Hul R, Plaisier P, Jeekel J, et al. Extracorporeal shock-wave lithotripsy of pancreatic duct stones: immediate and long-term results. Endoscopy $1994 ; 26: 573-8$

21. Ohara H, Hoshino M, Hayakawa T, et al. Single application extracorporeal shock wave lithotripsy is the first choice for patients with pancreatic duct stones. Am J Gastroenterol 1996; 91:1388-94

22. Dumonceau JM, Costamagna G, Tringali A, et al. Treatment for painfu calcified chronic pancreatitis: extracorporeal shock wave lithotripsy versus endoscopic treatment: a randomised controlled trial. Gut 2007; 56:545-52.

23. Dumonceau JM, Delhaye M, Tringali A, et al. Endoscopic treatment of chronic pancreatitis: European Society of Gastrointestinal Endoscopy (ESGE) Clinical Guideline. Endoscopy 2012; 44:784-800.

24. Costamagna G, Bulajic M, Tringali A, et al. Multiple stenting of refractory pancreatic duct strictures in severe chronic pancreatitis: long-term results. Endoscopy 2006; 38:254-9

25. Talukdar R, Reddy DN. Pain in chronic pancreatitis: managing beyond the pancreatic duct. World J Gastroenterol 2013; 19:6319-28.

26. Cremer M, Devière J, Delhaye $M$, Baize M, Vandermeeren A. Stenting in severe chronic pancreatitis: results of medium-term follow-up in seventysix patients. Endoscopy 1991; 23:171-6.

27. Eleftherladis N, Dinu F, Delhaye $M$, et al. Long-term outcome after pancreatic stenting in severe chronic pancreatitis. Endoscopy 2005 37:223-30.

28. Vitale GC, Cothron K, Vitale EA, et al. Role of pancreatic duct stenting in the treatment of chronic pancreatitis. Surg Endosc 2004; 18:1431-4.

29. Binmoeller KF, Jue $P$, Seifert $H$, et al. Endoscopic pancreatic stent drainage in chronic pancreatitis and a dominant stricture: long-term results. Endoscopy 1995; 27:638-44.

30. Eisendrath $P$, Devière J. Expandable metal stents for benign pancreatic duct obstruction. Gastrointest Endosc Clin N Am 1999; 9:547-54.

31. Park do H, Kim MH, Moon SH, et al. Feasibility and safety of placement of a newly designed, fully covered self-expandable metal stent for refractory benign pancreatic ductal strictures: a pilot study (with video). Gastrointes Endosc 2008; 68:1182-9.

32. Moon SH, Kim MH, Park do H, et al. Modified fully covered self expandable metal stents with antimigration features for benign pancreaticduct strictures in advanced chronic pancreatitis, with a focus on the safety profile and reducing migration. Gastrointest Endosc 2010; 72:86-91.
33. Forsmark CE. Management of chronic pancreatitis. Gastroenterology 2013; 144:1282-91.

34. Díte $\mathrm{P}$, Ruzicka M, Zboril V, Novotný I. A prospective, randomized trial comparing endoscopic and surgical therapy for chronic pancreatitis. Endoscopy 2003; 35:553-8.

35. Cahen DL, Gouma DJ, Nio Y, et al. Endoscopic versus surgical drainage of the pancreatic duct in chronic pancreatitis. N Engl J Med 2007; 356:676-84.

36. Cahen DL, Gouma DJ, Laramée P, et al. Long-term outcomes of endoscopic vs surgical drainage of the pancreatic duct in patients with chronic pancreatitis. Gastroenterology 2011; 141:1690-5.

37. Adler DG, Lichtenstein D, Baron TH, et al. The role of endoscopy in patients with chronic pancreatitis. Gastrointest Endosc 2006; 63:933-7.

38. Abdallah AA, Krige JE, Bornman PC. Biliary tract obstruction in chronic pancreatitis. HPB (Oxford) 2007; 9:421-8.

39. Draganov $P$, Hoffman B, Marsh W, Cotton P, Cunningham J. Long-term outcome in patients with benign biliary strictures treated endoscopically with multiple stents. Gastrointest Endosc 2002; 55:680-6.

40. Kahl S, Zimmermann S, Genz I, et al. Risk factors for failure of endoscopic stenting of biliary strictures in chronic pancreatitis: a prospective follow-up study. Am J Gastroenterol 2003; 98:2448-53.

41. Pozsár J, Sahin P, László F, Forró G, Topa L. Medium-term results of endoscopic treatment of common bile duct strictures in chronic calcifying pancreatitis with increasing numbers of stents. J Clin Gastroenterol 2004; 38:118-23.

42. Cahen DL, Rauws EA, Gouma DJ, Fockens P, Bruno MJ. Removable fully covered self-expandable metal stents in the treatment of common bile duct strictures due to chronic pancreatitis: a case series. Endoscopy 2008; 40:697-700.

43. Poley JW, Cahen DL, Metselaar HJ, et al. A prospective group sequential study evaluating a new type of fully covered self-expandable metal stent for the treatment of benign biliary strictures (with video). Gastrointest Endosc 2012; 75:783-9.

44. Behm B, Brock A, Clarke BW, et al. Partially covered self-expandable metallic stents for benign biliary strictures due to chronic pancreatitis. Endoscopy 2009; 41:547-51.

45. Banks PA, Bollen TL, Dervenis C, et al; Acute Pancreatitis Classification Working Group. Classification of acute pancreatitis--2012: revision of the Atlanta classification and definitions by international consensus. Gut 2013; 62:102-11.

46. Bradley EL 3rd. A clinically based classification system for acute pancreatitis. Summary of the International Symposium on Acute Pancreatitis, Atlanta, Ga, September 11 through 13, 1992. Arch Surg 1993; 128:586-90.

47. Andrén-Sandberg A, Dervenis C. Pancreatic pseudocysts in the 21st century. Part I: classification, pathophysiology, anatomic considerations and treatment. JOP 2004; 5:8-24

48. Andrén-Sandberg A, Dervenis C. Pancreatic pseudocysts in the 21st century. Part II: natural history. JOP 2004; 5:64-70.

49. Gumaste UV, Dave PB. Pancreatic pseudocyst drainage--the needle or the scalpel? J Clin Gastroenterol 1991; 13:500-5.

50. Spivak H, Galloway JR, Amerson JR, et al. Management of pancreatic pseudocysts. J Am Coll Surg 1998; 186:507-11.

51. Boggi U, Di Candio G, Campatelli A, Pietrabissa A, Mosca F. Nonoperative management of pancreatic pseudocysts. Problems in differential diagnosis. Int J Pan creatol 1999; 25:123-33.

52. Cahen D, Rauws E, Fockens $P$, et al. Endoscopic drainage of pancreatic pseudocysts: long-term outcome and procedural factors associated with safe and successful treatment. Endoscopy 2005; 37:977-83.

53. Trevino JM, Tamhane A, Varadarajulu S. Successful stenting in ductal disruption favorably impacts treatment outcomes in patients undergoing transmural drainage of peripancreatic fluid collections. J Gastroenterol Hepatol 2010; 25:526-31

54. Varadarajulu S, Bang JY, Sutton BS, et al. Equal efficacy of endoscopic and surgical cystogastrostomy for pancreatic pseudocyst drainage in a randomized trial. Gastroenterology 2013; 145:583-90.e1.

55. Rosso E, Alexakis N, Ghaneh P, et al. Pancreatic pseudocyst in chronic pancreatitis: endoscopic and surgical treatment. Dig Surg 2003; 20:397-406

56. Téllez-Ávila FI, Villalobos-Garita A, Ramírez-Luna MÁ. Use of a novel covered self-expandable metal stent with an anti-migration system for endoscopic ultrasound-guided drainage of a pseudocyst. World J Gastrointest Endosc 2013; 5:297-9.

57. Gress F, Schmitt C, Sherman S, Ikenberry S, Lehman G. A prospective randomized comparison of endoscopic ultrasound- and computed tomography-guided celiac plexus block for managing chronic pancreatitis pain. Am J Gastroenterol 1999; 94:900-5. 
58. Santosh D, Lakhtakia S, Gupta R, et al. Clinical trial: a randomized tria comparing fluoroscopy guided percutaneous technique vs. endoscopic ultrasound guided technique of coeliac plexus block for treatment of pain in chronic pancreatitis. Aliment Pharmacol Ther 2009; 29:979-84.

59. Puli SR, Reddy JB, Bechtold ML, Antillon MR, Brugge WR. EUS-guided celiac plexus neurolysis for pain due to chronic pancreatitis or pancreatic cancer pain: a meta-analysis and systematic review. Dig Dis Sci 2009; 54:2330-7.

60. Kaufman M, Singh G, Das S, et al. Efficacy of endoscopic ultrasound-guided celiac plexus block and celiac plexus neurolysis for managing abdominal pain associated with chronic pancreatitis and pancreatic cancer. J Clin Gastroenterol 2010; 44:127-34.
61. Gress F, Schmitt C, Sherman S, et al. Endoscopic ultrasound-guided celiac plexus block for managing abdominal pain associated with chronic pancreatitis: a prospective single center experience. Am J Gastroenterol 2001; 96:409-16.

62. Sarner M, Cotton PB. Classification of pancreatitis. Gut $1984 ; 25: 756-9$.

63. Hookey LC, RioTinto R, Delhaye M, et al. Risk factors for pancreatitis after pancreatic sphincterotomy: a review of 572 cases. Endoscopy 2006; 38:670-6.

64. Okolo PI 3rd, Pasricha PJ, Kalloo AN. What are the long-term results of endoscopic pancreatic sphincterotomy? Gastrointest Endosc 2000; 52:15-9. 